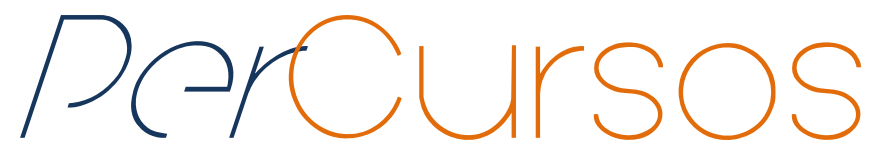

\title{
Resenha do livro "Histórias de escravos e senhores em uma região de imigração europeia"
}

MOREIRA, Paulo Roberto Staudt; MUGGE, Miquéias Henrique. Histórias de escravos e senhores em uma região de imigração europeia. São Leopoldo, RS: Oikos, 2014.133 p.

João Augusto Brancher Fuck

Doutorando do Programa de Pós-Graduação em

Planejamento Territorial e Desenvolvimento

Socioambiental - PPGPLAN da Universidade do

Estado de Santa Catarina - UDESC.

Brasil

joaooabf@gmail.com

\section{Para citar esta resenha:}

FUCK, João Augusto Brancher. Resenha do livro "Histórias de escravos e senhores em uma região de imigração europeia”. Revista PerCursos. Florianópolis, v. 17, n. 35, p. 253 - 258, set./dez. 2016.

\section{DOI: 10.5965/1984724617352016253}

http://dx.doi.org/10.5965/1984724617352016253 
O livro de autoria de Paulo Roberto Staudt Moreira' e Miquéias Henrique Mugge ${ }^{2}$, ambos com formação na área de História, retrata a convivência entre senhores e escravos no território imperial da Colônia de São Leopoldo, no século XIX. Neste conciso, mas interessante livro, que conta com uma pequena introdução e quatro capítulos, os autores buscam demonstrar como a escravidão se fez presente em uma região de imigração alemã, tida como um local de preservação dos princípios da família e do trabalho. Destacam, ainda, a "aquisição" de escravos como objetivo almejado por muitos imigrantes que obtinham alguma ascensão à elite local nessa colônia.

O livro inicia descrevendo o matrimônio de Joaquim e Maria de Paso, em 1844, no extremo sul do país, abençoado por um sacerdote luterano. Ambos eram escravos de um imigrante alemão, afeito às causas da Revolução Farroupilha. O casamento foi registrado em alemão, na comunidade evangélica de São Leopoldo. Com o relato deste caso, é trazida à tona a importância dos livros de registro de comunidades evangélico-luteranas e católicas para obtenção de vasta informação acerca da imigração alemã e da escravidão. Além dessa fonte de informação, são levantados dados estatísticos e argumentos para demonstrar o peso e a capilaridade da escravidão no Rio Grande do Sul, especialmente nessa região. Ainda, os autores realizam uma crítica ao que denominam de "historiografia apologética", que busca, como um "véu de invisibilidade", deixar de lado a escravidão nesse local. Ressalta-se que ao longo do texto são apresentadas imagens do acervo do Museu Histórico Visconde de São Leopoldo.

Com essas informações, o primeiro capítulo é iniciado trazendo a trajetória do imigrante Paulus Hammel, retomando a errônea afirmação de que os imigrantes alemães não eram afeitos ao escravismo. O caso é justamente apresentado para retratar o contrário. Como ocorre nos demais capítulos, os autores realizam uma pequena caracterização do personagem central, com descrição de informações pessoais e familiares, como fatos da época. Vale ressaltar que, no desenrolar dessas pequenas narrativas, muitas outras acabam surgindo. Apesar de não se ter informações sobre a

\footnotetext{
1 Doutor em História pela Universidade Federal do Rio Grande do Sul. Atualmente é professor da Universidade do Vale do Rio dos Sinos.

${ }^{2}$ Doutor em História social pela Universidade Federal do Rio de Janeiro. Atua como Postdoctoral Research Associate na Woodrow Wilson School of Public and International Affairs, Princeton University (EUA).
} 
aquisição do escravo por Paulus Hammel, a trajetória de sua família é apresentada, para destacar uma questão bastante importante, sobre as heranças imateriais, haja vista a presença de imigrantes na guerra e as oportunidades de mobilidade social por meio de favores reais (dívidas de sangue). Ainda com vistas à trajetória de Hammel, os autores utilizam a descrição realizada pelo também imigrante alemão Hörmeyer em seu "guia para emigrantes" sobre Porto Alegre, destacando a possibilidade de adquirir um escravo, após ganhos no Brasil, "como símbolo de status ou como auxílio em seus ofícios" (MOREIRA; MUGGE, 2014, p. 33). No guia há detalhes sobre as características dos escravos, atividades que realizavam, alimentação, entre outros. Os autores também relatam brevemente a trajetória do agrimensor João Martinho Buff, imigrante e também senhor de escravos. Com isso, afirma-se que os imigrantes alemães mudaram e foram mudados pela realidade encontrada, enfrentando diversos percalços na colônia.

No segundo capítulo é descrita a passagem do serrano Bento, com seu senhormoço, conduzindo uma tropa, na Vila de São Leopoldo em 1866, bem como a presença de outros cativos. Serrano era a denominação dada aos pecuaristas, que vendiam o gado para adquirir outros produtos necessários, como o sal. São Leopoldo era um centro comercial, com "contatos e experiências sociais e étnicas diversas" (MOREIRA; MUGGE, 2014, p. 42). Ambos pararam na casa de comércio do imigrante alemão Nicolau Stumpf. A chegada do serrano Bento é utilizada como pano de fundo para descrever os sete escravos daquele teuto-senhor, contando somente os registros oficiais. De acordo com a informação dos livros de batismo, esse número chegava a 14 no período de 1847 a 1872 . Descrevem ainda um $15^{\circ}$ escravo, denominado de ingênuo, definição dada após a Lei 2.040 de 28/09/1871 (Lei do Ventre Livre), que libertava os filhos das escravas ainda em seus ventres. Entretanto, essas crianças não ficavam livres, como se imaginava. Outra questão que surge é a concessão de alforrias para os escravos, concedidas por meio do pagamento de altas multas ou de prestação de serviços ao senhor por um determinado período de tempo. No capítulo, ainda são destacados temas como o consumo de bebidas alcoólicas, inclusive com relatos de suas propriedades medicinais, e a prática comum dos escravos adotarem o sobrenome do senhor, especialmente entre os protestantes. Também é relatado o aluguel de cativas como amas-de-leite, prática muito rentável, 
levando muitas vezes ao infanticídio por parte dos senhores. O capítulo é finalizado com a retomada da descrição inicial do serrano Bento chegando ao comércio de Nicolau; locais como esses, apesar da rica interação, eram vistos com desconfiança pelas autoridades.

O terceiro capítulo narra o trabalho de parto da liberta Ana Blauth, ex-escrava de Nicolau Blauth, ocorrido em um anoitecer de março de 1885. Após a descrição da trajetória de ambos, coloca-se que o filho de Ana nasceu morto, provavelmente em decorrência do trabalho pesado a que era submetida. Em julho do mesmo ano, o promotor acusa Ana de infanticídio, tendo em vista que ela enterrou a criança no terreno do seu ex-senhor sem comunicá-lo sobre os motivos do ocorrido. Esse ano é marcado pela retomada do movimento abolicionista, partindo dos próprios escravos, momento no qual muitas alforrias foram concedidas mediante cumprimento de serviços gratuitos pelos libertos, prática seguida pelo teuto-senhor Blauth. Cabe destacar que, ao longo do livro, os autores buscaram corroborar as informações com dados estatísticos que evidenciavam tais fatos. Ainda sobre as alforrias, nelas não apareciam o ofício dos escravos, ressaltando somente o papel benevolente dos senhores em libertá-los. Ao final, Ana foi absolvida da acusação com a afirmação racista de que "[...] a ínfima condição social de Ana (ex-escrava) impedia que ela tivesse sentimentos como honra e vergonha, motivos vistos como motores de um provável crime" (MOREIRA; MUGGE, 2014, p. 78); opinião que refletia a de muitas autoridades da época, no momento final do escravismo brasileiro.

No último capítulo, também o mais longo do livro, é descrito o caso do roubo da carta de alforria do preto Pedro Allgayer. O objetivo, neste momento, é analisar a trajetória de escravos que obtinham a alforria e a realidade encontrada por esses sujeitos. Para isso, parte de documento judicial sobre o crime de roubo de uma alforria, em 1884, é utilizado para demonstrar a importância desses documentos na recuperação das informações sobre a escravidão na região. As dificuldades de buscar informações dessa população após a emancipação são a ausência do registro da cor (diferente do período anterior, em que era utilizada com o objetivo de definir a hierarquia social) e a adoção do sobrenome do ex-senhor (uma forma de afirmação social dos libertos, ao utilizar esse sobrenome, de pertencimento à comunidade, que acabava gerando uma proteção 
comunitária). Foi o que ocorreu com Pedro, com toda a mobilização da polícia e vizinhos para capturar o ladrão. Além disso, todas as testemunhas o identificaram como "[...] preto livre Pedro Allgayer" (MOREIRA; MUGGE, 2014, p. 88). Após a discussão realizada em torno do roubo desta carta, destaca-se que a obtenção da alforria marcava uma trajetória positiva e bem-sucedida, por isso era ressaltada nos documentos do Judiciário. Entretanto, havia diferença entre aquelas obtidas gratuitamente ou mediante pagamento e indenização ao senhor. É feita uma caracterização dos curtumes na região e da inserção dos imigrantes alemães na atividade. Dados do censo de 1872 são utilizados para descrever características dos escravos, ressalvando que, apesar de o censo ser uma importante fonte de informação, estavam incompletos. Retomando o roubo da carta de Pedro, há informações sobre a regulamentação dos serviços de criados domésticos em Porto Alegre, levantando hipóteses sobre a motivação do réu para cometer tal crime. Os autores, por meio do depoimento de Pedro, analisam sua rede de parentesco e a importância desta como aliança e proteção; compartilhavam experiências da cultura do local de origem, bem como da escravidão. A mobilização da comunidade e da polícia em prol de Pedro levanta a questão sobre as influências da permanência desses libertos próximos às regiões em que foram escravos, “[...] o reconhecimento comunitário advindo desta territorialidade poderia angariar para estes africanos alguma forma de auxílio, que era sempre bem-vindo na precária existência que levavam" (MOREIRA; MUGGE, 2014, p. $115)$.

Em poucas páginas, ainda com diversos relatos pontuais de escravos e senhores da época, os autores mostram a multiplicidade de experiências de cativos e senhores na colônia de São Leopoldo. Finalizam listando várias famílias imigrantes alemãs que foram possuidoras de escravos, mostrando a importância desse processo na região e como " $\mathrm{A}$ experiência migratória não os fez um quisto; tampouco os isolou geográfica e socialmente" (MOREIRA; MUGGE, 2014, p. 123). De forma clara e com estudos de caso, descrevem situações e buscam quebrar paradigmas em torno da imigração alemã e da escravidão. Com dados principalmente de registros de batismos, casamentos e processos criminais, mostram o peso e a importância da escravidão na região, evidenciando também, por meio de informações estatísticas, que nem por um piscar de olhos essa 
prática pode ser negada ou considerada invisível. Os acontecimentos relatados, na maioria das vezes trágicos, são importantes para conhecer práticas realizadas, muitas das quais influenciam até hoje a convivência social.

Recebida em: 06/12/2016 Aprovada em: 08/02/2017 